Revista lus et Praxis, Año 25, No 2, 2019, pp. 261 - 298

ISSN 0717 - 2877

Universidad de Talca - Facultad de Ciencias Jurídicas y Sociales

Legítima defensa y elección del medio menos lesivo

Juan Sebastián Vera S.

Trabajo recibido el 13 de noviembre de 2017 y aprobado el 2 de mayo de 2019

\title{
Legítima defensa y elección del medio menos lesivo
}

\author{
SelF DEFENSE AND CHOOSING THE LESS DAMAGING MEAN
}

Juan Sebastián Vera S.

\begin{abstract}
RESUMEN
La legítima defensa es procedente como causal de justificación cuando la acción defensiva ha sido racional y necesaria. Un criterio que se emplea para valorar la acción defensiva consiste en que esta sea el resultado de la elección del medio menos lesivo por parte del sujeto. Este trabajo pretende justificar que dicho criterio es derrotable y una mala generalización acerca de la "necesariedad" de la defensa, y, además, no cumple con la máxima "debe implica puede", sobre la base de estudios de la neurobiología y de la psicología.
\end{abstract}

\section{ABSTRACT}

Self defense justifies actions if the defense has been rational and necessary. One of the criteria applied to value the action, is that the defender should use only the minimum force required to achieve the defensive goal. Thus, the defender should choose the less damaging mean from all the available options to defend himself (lesser evil). This paper attempts to give reasons to argue that the criterion of "minimum force" is defeatable, is a bad generalization about defensive actions and it is contrary to the criterion "ought implies can". I will back up these statements using empirical research from Neurobiology and Psychology.

\section{Palabras Clave}

Legítima defensa, medio menos lesivo, derrotabilidad, generalización

KEY WORDS

Self defense, less damaging means, defeasibility, generalization

\section{Introducción}

No han sido pocos los problemas que han evidenciado los autores cuando se enfrentan al desarrollo doctrinal de los requisitos de la legítima defensa. Aunque no puedo entrar con mayor profundidad en los mismos, es posible encontrar dos grandes razones que permitan inferir la dificultad del tratamiento doctrinal: en

\footnotetext{
* Doctor en Derecho Universidad de Barcelona. Profesor de Derecho Penal, Derecho Procesal Penal y Derecho Probatorio en la Universidad Austral de Chile. Dirección postal: Facultad de Ciencias Jurídicas y Sociales, Universidad Austral de Chile, Isla Teja s/n, Valdivia, Chile. Correo electrónico: juan.vera@ uach.cl. Quisiera expresar mi gratitud a los profesores Dra. Mirentxu Corcoy Bidasolo, Dr. Sebastián Agüero San Juan y al Dr. Pablo Lizana por sus importantes comentarios para este trabajo. Dedicado al prof. Francesc Baldó, cuyo trabajo ha inspirado gran parte de mis reflexiones sobre la legítima defensa.
} 
primer lugar, la legítima defensa no nace vinculada al desarrollo de la moderna teoría jurídica del delito y del derecho penal liberal de la llustración. Por el contrario, podríamos decir que la legítima defensa presenta una configuración completamente práctica, que ha acompañado a la especie humana como muestra de racionalidad y justicia desde el mismísimo momento en que se ha podido dejar constancia escrita de la presencia de los seres humanos en la tierra. No por nada se ha establecido que uno de sus posibles fundamentos es el instinto de autoconservación ${ }^{1}$. Por todo lo anterior se afirma que la legítima defensa es una institución atemporal, que no posee historia ${ }^{2}$ y que no ha conquistado un lugar entre las eximentes de responsabilidad penal, sino que lo ha mantenido ${ }^{3}$. Incluso es posible encontrar antecedentes de la misma en el derecho romano ${ }^{4}$. Esta evolución genera algunos problemas cuando se intenta situar a la legítima defensa como una causa de justificación dentro de la moderna teoría del delito, pues dicho "encaje" no está exento de dificultades dogmáticas. Por ejemplo, por principio se debe erradicar del análisis de la legítima defensa cualquier indicador ponderativo de la proporcionalidad entre los bienes jurídicos en juego pues, de lo contrario, se podría producir un solapamiento con el estado de necesidad justificante ${ }^{5}$. En otro sentido, la legítima defensa es una causa de justificación que pertenece al análisis del injusto, por lo que, en principio, su procedencia no debería estar moderada por elementos psicológicos presentes en el defensor. En este sentido, las características personales del autor, desde un punto de vista de una teoría del delito tradicional y mayoritaria, deberían ser relevantes (aunque no exclusivas) respecto del análisis de la imputación subjetiva o personal, mas no del análisis de la ilicitud de la conducta.

El aspecto principal que modera la discusión interpretativa de la legítima defensa en sede penal son, precisamente, sus efectos justificatorios. En efecto, los enunciados fácticos que puedan ser subsumidos o captados por esta causal de justificación devendrán, por ese solo hecho, como permitidos, autorizados, lícitos y, por tanto, no susceptibles de ser sancionados penalmente. Es decir, la discusión acerca de los alcances interpretativos de la legítima defensa y sus requisitos, en definitiva, es un debate acerca de la licitud que presentan o debieran presentar ciertos actos. Por otro lado, la procedencia de la legítima defensa

\footnotetext{
1 Cousiño (1979), p. 171; PACHeCO (1848), p. 160.

2 Jiménez de AsúA (2005), p. 138. Al respecto, véase opinión de Cousiño (1979), p. 172: "ignorar la historia de algo en toda su amplitud, no significa que ese algo carezca de historia".

3 Politoff y Matus (2002), pp. 127 y ss.

4 Domínguez (2011), pp. 19 y ss.

${ }^{5}$ Sobre el criterio de proporcionalidad como moderador de la defensa necesaria, véase SANGero (2006), pp. 166 y ss.
} 
como causal de justificación tradicionalmente puede conceptualizarse como un "permiso" dentro de la prohibición general de la conducta justificada. Es decir, la legítima defensa es una autorización excepcional y especial para realizar un comportamiento típico prohibido si y solo si se obra en defensa de la persona, sus derechos o los de otros (artículo 10, Nos. 4, 5 y 6, CP).

Por ello, muchas veces, aunque no se diga, la interpretación acerca del alcance de los requisitos de la legítima defensa no es una operación únicamente centrada en la determinación semántica de ciertos conceptos que emplea la ley en el citado artículo del Código Penal, sino también una decisión política acerca de castigar o no ciertos actos que se intentan subsumir en esta causal de justificación. Ello agrega una indudable carga política a la discusión, que no la exime de estar en un permanente contacto con diversas realidades sociales, a las cuales se discute aplicar los efectos justificatorios de esta causal de justificación, y de estar atentos a los efectos político-criminales de la aceptación de la autorización o no.

En este escenario se sitúan los problemas interpretativos de esta causal de justificación y, en especial, del que será objeto de este trabajo. En efecto, para que sea procedente la legítima defensa se exige que la acción defensiva sea la expresión de "una necesidad racional del medio empleado para impedir o repeler" la agresión ilegítima. De esta forma, la determinación del sentido y alcance de este requisito, en definitiva, devendrá en la determinación del límite de la autorización concedida a todos los ciudadanos para defenderse ${ }^{6}$. Así, uno de los criterios que se emplean para llevar a cabo esta labor es aquel que señala que la defensa será necesaria cuando la víctima haya optado por el medio menos lesivo de defensa.

En este sentido, la Corte Suprema, en sentencia de 3 de mayo de 2007, considera que "... frente al ataque de un individuo y la asechanza de varios más, encontrándose la víctima en el suelo y prácticamente inmovilizada, un disparo parece haber sido lo único que podía hacer en su defensa, porque no resulta posible tampoco suponer cuál otro habría sido un elemento más efectivo y menos dañino, al cual hubiese podido echar mano en la situación en que se encontraba" ${ }^{7}$.

Por su parte, la Corte de Apelaciones de San Miguel ha señalado que "en la especie, se ha impugnado la racionalidad y proporcionalidad del medio empleado, es decir, si para repeler la agresión de que estaba siendo objeto, el imputado empleó un medio racional. A este respecto se ha señalado que

\footnotetext{
${ }^{6}$ Politoff et al. (2003), p. 219.

7 Sentencia de Corte Suprema de 3 de mayo de 2007, ingreso № 6466-2005, considerando $5^{\circ}$, sentencia de reemplazo. (El destacado es nuestro).
} 
el defensor puede usar el medio que sea necesario para impedir o repeler la agresión, pero no puede ir más allá de lo estrictamente necesario. Debe recurrir al medio menos lesivo de los que estén a su alcance"s. En igual sentido, la Corte de Apelaciones de Antofagasta, en sentencia de 8 de mayo de 2014, ha señalado que "El artículo $10 \mathrm{~N}^{\circ} 4$ establece que existe 'necesidad racional del medio empleado para impedirla o repelerla', es decir, que ésta sea el medio imprescindible para repeler la agresión. Exigiendo además, que sea racionalmente necesario, es decir, que sea el menos lesivo de aquellos que están al alcance del que se defiende, para ello, debe apreciarse la realidad de las circunstancias concurrentes, tanto personales, como el hecho mismo" ${ }^{\prime \prime}$. Asimismo, la Corte de Apelaciones de La Serena, valiéndose de las palabras de Cury al respecto, señala que la defensa "importa que la reacción sea necesaria, esto es, que, dadas las circunstancias, el sujeto no disponga de otra forma menos enérgica de defenderse con éxito"10. En igual sentido, la Corte de Apelaciones de Valdivia señala en sentencia de fecha 23 de diciembre de 2004 que "en la especie se encuentran acreditados todos los requisitos del artículo $10 \mathrm{~N}^{\circ}$ s. 4 y 5 del Código Penal, en especial la circunstancia segunda del artículo $10 \mathrm{~N}^{\circ} 4$ en atención a que el medio empleado para repeler la agresión fue proporcional a ella, sobre todo si se tiene en cuenta la superior capacidad de la víctima y el grado de descontrol en que se encontraba y la ausencia de otros medios menos lesivos con los cuales podía contar aquella para enfrentar al agresor"11.

Como se ve, la regla de opción del medio menos lesivo no solo tiene presencia en la doctrina penal, sino que también se halla bastante incorporada en la jurisprudencia de los tribunales de justicia, como Cortes de Apelaciones y Corte Suprema.

En este trabajo analizaré la conveniencia o no del criterio de la opción del medio menos lesivo para considerar la acción defensiva como racional y necesaria. En primer lugar, para ello realizaré algunas consideraciones desde la perspectiva de la dogmática penal. En segundo lugar, confrontaré lo anterior con ciertas investigaciones sobre la toma de decisiones en contexto de peligro o bajo presión y estrés. En tercer lugar, intentaré cuestionar la validez del

\footnotetext{
${ }^{8}$ Sentencia de Corte de Apelaciones de San Miguel, rol No 1230-2016, de fecha 14 de julio de 2016, considerandos $8^{\circ}$ y $9^{\circ}$. (El destacado es nuestro).

9 Sentencia de Corte de Apelaciones de Antofagasta, rol № 100-2014, de fecha 8 de mayo de 2014, considerando $6^{\circ}$.

10 Sentencia de Corte de Apelaciones de la Serena, rol No 89-2005, de fecha 6 de mayo de 2005, considerando $9^{\circ}$. (El destacado es nuestro).

11 Sentencia de la Corte de Apelaciones de Valdivia, rol № 256-2014, de 23 de diciembre de 2004, considerando $10^{\circ}$. (El destacado es nuestro).
} 
criterio de la opción del medio menos lesivo considerando la derrotabilidad de la regla de la defensa necesaria construida sobre la base de dicho criterio, y su deficiente potencial o "rendimiento" cognitivo. Asimismo, cuestionaré la compatibilidad de este criterio con la máxima "debe implica puede", que se atribuye a Kant, lo cual redundará en la pertinencia o no de la regla como expresión de la racionalidad legislativa.

Por último, sobre la base de todo lo anterior, me referiré a si ciertas circunstancias personales de la víctima deben o no ser consideradas en sede de justificación penal.

\section{Descripción de la regla de opción del medio menos lesivo en Chile y en el derecho comparado}

La redacción del Código Penal chileno, en relación con el requisito de la necesidad racional de la defensa, no es del todo clara ni muy feliz. En efecto, ello puede advertirse a partir de la aprobación en general que se hizo de la redacción del Código Penal español de 1848, modificado en el año 1850, lo que no permitió una discusión abundante sobre la forma de tipificación de esta causal de justificación ${ }^{12}$. En efecto, el artículo 10, 4 ${ }^{\circ}$ considera que están exentos de responsabilidad criminal:

"4. El que obra en defensa de su persona o derechos, siempre que concurran las circunstancias siguientes:

Primera. Agresión ilegítima.

Segunda. Necesidad racional del medio empleado para impedirla o repelerla.

Tercera. Falta de provocación suficiente del que se defiende".

Una interpretación literal del requisito de la necesidad racional de la defensa podría llevarnos a sostener que lo importante es que el "medio" empleado sea racional. En este sentido, la redacción de la ley es poco clara, pues sugiere la idea de un equilibrio instrumental ${ }^{13}$. Un primer problema de esta perspectiva es que podemos emplear un criterio de corte "aritmético" o "matemático"14 entre el medio utilizado para la defensa y la agresión, lo cual es ampliamente

\footnotetext{
12 Olivares (2013), p. 4.

13 Cury (2005), p. 401.

14 En este sentido, por ejemplo, Etcheberry (1997), p. 256, considera que "hay cierta tendencia de parte de los tribunales para atribuir a este requisito un sentido de equivalencia matemática entre la naturaleza del ataque y la de la defensa".
} 
rechazado y solo presenta utilidad didáctica. Por ello, según la doctrina, la necesidad racional ha de manifestarse no solo en los instrumentos usados para reaccionar contra el ataque, sino en la totalidad de dicha reacción, lo que permite que en casos excepcionales se usen medios que en circunstancias corrientes resultarían excesivos ${ }^{15}$.

La necesidad racional del medio empleado se ha traducido, en una de sus aristas, en una ponderación entre el bien jurídico afectado por la agresión y el bien jurídico afectado por la defensa. De ahí que, por ejemplo, parte de la doctrina nacional considere que la necesidad racional del medio empleado se pueda entender como una exigencia de un criterio de proporcionalidad ("el interés dañado no debe ser mucho mayor que el interés defendido"16). Por otro lado, también se ha recurrido al criterio de subsidiariedad ${ }^{17}$ que, a su vez, se vincula con los casos que la dogmática penal considera ejemplos de "restricción ético-social" de la legítima defensa ${ }^{18}$. En otro sentido, la necesidad de la defensa también se ha relacionado con la potencialidad de los medios utilizados para afectar los bienes jurídicos. Sin embargo, esta interpretación puede aparejar importantes problemas para resolver los casos en donde, a priori, el medio es potencialmente muy lesivo (lo cual podría indicar su irracionalidad en su empleo), pero, en virtud de las circunstancias, es el único disponible y utilizable para la víctima.

La necesidad racional también se ha vinculado con una valoración sobre los medios disponibles para la defensa, de forma que el individuo que se defienda utilice de forma restrictiva esta habilitación excepcional para afectar bienes jurídicos del agresor.

Como acertadamente reconoce Wilenmann, en el derecho penal hispanoamericano la cláusula de "necesidad racional del medio empleado" ha sido utilizada para introducir, sin control sistemático, criterios de proporcionalidad y subsidiariedad ${ }^{19}$. Con ello se generan indudables problemas en la interpretación dogmática de la legítima defensa como instituto de la teoría del delito y su fundamentación.

Así, y como se ve, el sentido y alcance de la expresión "necesidad racional del medio empleado" está lejos de ser una cuestión completamente zanjada y

\footnotetext{
${ }^{15}$ Cury (2005), p. 374: "Así, el viejecillo raquítico que es atacado a puño limpio por un fornido mocetón, puede echar mano de un arma de fuego para defenderse...".

${ }^{16}$ En este sentido, sentencia de Corte Suprema, rol № 1099-2003, de fecha 17 de octubre de 2005, considerando $14^{\circ}$.

17 Politoff et al. (2003), p. 220. En contra, la de subsidiariedad, Cury (2005), p. 375.

${ }^{18}$ Respectos a las restricciones ético-sociales, véase Roxın (1982), pp. 297 y ss.

19 WiLenMANN (2015), p. 624.
} 
libre de dificultades. Con justa razón, entonces, parte de la doctrina nacional ha entendido que la redacción sitúa la importancia en un vocablo instrumental (medio) en circunstancias que hay que entender que la expresión se refiere a la "necesidad racional de la manera de defenderse" ${ }^{20}$.

En este punto, la doctrina española -que se pronuncia sobre la base de un texto legal bastante similar al nuestro- distingue entre necesidad abstracta de la defensa y necesidad concreta de la defensa. El Código Penal español exige la "necesidad racional del medio empleado para repeler o impedir la agresión".

En este sentido es posible distinguir entre la necesidad de la defensa (en sentido amplio o genérico ${ }^{21}$ ) y la necesidad del medio empleado como dos cosas distintas. La primera -en palabras de Mir Puig-se corresponde con la necesidad abstracta de la defensa y su ausencia no permitiría apreciar ni eximente completa ni incompleta ${ }^{22}$. Es decir, se identifica con la aparición de un riesgo para algunos de los bienes jurídicos penalmente protegidos ${ }^{23}$, que no están ya protegidos y seguros y, por tanto, obligan a realizar una actuación para evitar que ese riesgo se realice ${ }^{24}$. La segunda, "necesidad concreta de la defensa", se refiere a cómo la necesidad de la defensa se concreta en la utilización de un medio, que en caso de ser excesivo (exceso intensivo ${ }^{25}$ ) podría dar lugar a la apreciación de la eximente incompleta ${ }^{26}$. Se trataría de ponderar la aptitud, racionalidad y peligrosidad potencial de los medios utilizados en la defensa ${ }^{27}$, para posteriormente escoger aquellos que sean los medios menos gravosos disponibles para

20 ETCHeBERRY (1997), p. 254.

21 Matellanes (2010), pp. 268 y ss.

22 Mir Puig (2015), p. 453; Matellanes (2010), p. 268.

${ }^{23}$ Cobo del Rosal (2011), p. 126. Como explica Matellanes (2010), p. 268, "cuando un bien jurídico está siendo objeto de un ataque real, grave e inevitable, la situación de crisis en la que se encuentra hace que el agredido no tenga otra alternativa jurídica para imponer el Derecho más que repeler la agresión".

${ }^{24}$ LuzÓn (2002), pp. 879 y ss. Para Roxin (1997), pp. 628 y ss., la necesidad de la defensa se manifiesta de dos caracteres específicos: la idoneidad de la defensa y la elección del medio más benigno posible.

25 Sobre el exceso intensivo, véase Bolea (1998), pp. 614 y ss.

${ }^{26}$ MiR Puig (2015), p. 453. En este sentido, el autor considera que es necesario distinguir entre exceso extensivo y exceso intensivo. El primero se da cuando la defensa se prolonga por más tiempo del que dura la actualidad de la agresión. El segundo, que la agresión es actual, pero que la defensa podría y debería adoptar una intensidad lesiva menor. El exceso extensivo excluye la eximente completa e incompleta. Por su parte, el exceso intensivo excluye la presencia de la eximente completa, pero da lugar a la apreciación de la concurrencia de la eximente incompleta. En el mismo sentido de admitir la eximente incompleta en este caso, Cobo del Rosal (2011), p. 126; Matellanes (2010), p. 270; Luzón (2002), p. 880; LóPEZ (2010), p. 650, pero solo en el caso de que este exceso sea significativo de un error; Morillas (2004), p. 238; Quintero y Morales (2010), p. 535; Suárez-Mira et al. (2011), p. 163.

27 En este sentido, por ejemplo, Luzón (2002), p. 879. En el mismo sentido respecto de la importancia de la idoneidad de la defensa, Morillas (2004), p. 237; Luzón (2004), p. 406. 
impedir o repeler la agresión ${ }^{28}$. De ello se sigue que si se opta por la utilización de un medio que no sea el menos lesivo para repeler la agresión, entonces no se afecta la necesidad abstracta de la defensa, sino la concreta o de medios ${ }^{29}$.

Respecto de la racionalidad de la defensa, la doctrina considera que por ella se entiende una necesidad aproximada, no estricta, de defenderse desde una perspectiva ex ante ${ }^{30}$, apreciación que, desde luego, compartimos. Dicha perspectiva podrá ser determinada según el juicio de un tercer observador sensato $^{31}$. Faltará la necesidad concreta de la defensa cuando el sujeto pueda utilizar claramente un medio menos lesivo ${ }^{32}$. En este sentido, se recurre a la idea de proporcionalidad como criterio limitador de la acción defensiva en medios y modos $^{33}$, o en especie y medida de los medios utilizados ${ }^{34}$. Pero este criterio ha de utilizarse en sentido amplio ${ }^{35}$ o de manera flexible ${ }^{36}$. Ello, en cuanto si se efectuara en sentido estricto (proporcionalidad entre males), la legítima defensa pasaría a presentar una estructura muy similar a la del estado de necesidad. Por otro lado, no se ha hecho mención alguna a la proporcionalidad en la regulación

${ }^{28}$ Cobo del Rosal (2011), p. 126; Cuello y Mapelli (2011), p. 92 ; Matellanes (2010), p. 268; Diez (2011), p. 271; LÓPEZ (2010), p. 650; LuZÓN (2002), p. 881, considera que "generalmente (el medio) habrá de ser proporcional a la intensidad y peligrosidad de la agresión, pero puede haber casos en que no sea así dependiendo de las condiciones personales del defensor y agresor"; Luzón (2009), p. 121; Roxin (1997), p. 629; JAKOBS (1997), p. 472. Por su parte, ZugaldíA (2010), p. 315; ZiıIO (2012), p. 160; JESCHECK y WEIGEND (2002), p. 468, consideran la elección del medio menos lesivo para el agresor como aplicación del "principio de mínima lesividad del agresor".

${ }^{29}$ LuZÓN (1978), p. 403.

30 MIR (2015), p. 442. En este sentido, por ejemplo Luzón (2002), p. 88, considera que la racionalidad califica a la necesidad y no al medio, y por ella ha de entenderse una "creencia objetiva y racionalmente fundada ex ante en que era preciso recurrir a ese medio, aunque a posteriori se compruebe que realmente no era necesario". En el mismo sentido de la valoración ex ante de la necesidad de defensa, véase López (2010), p. 649; LuZÓn (2002), p. 412; ORTS y GonZÁlezZ (2008), p. 175; Zugaldía (2010), p. 314; JESCHECK Y WEIGEND (2002), p. 467; BALDÓ (1994), p. 309.

31 Roxin (1997), p. 631.

32 MIR (2015), p. 443. StRATENWERTH (2005), p. 200, considera importante en la determinación de la menor lesividad del medio las capacidades del defensor. En el mismo sentido, condicionando la necesidad de la defensa a la opción de medios menos lesivos, MAURACH y ZIPf (1994), p. 439.

33 Matellanes (2010), p. 269; López (2010), p. 649.

34 MuÑoz y García (2010), p. 326, consideran que la entidad de la defensa debe adecuarse a la entidad de la agresión. De lo contrario, no habría justificación plena y, a lo más, podría apreciarse el exceso intensivo. En contra de confundir la necesidad racional del medio empleado con el requisito de la proporcionalidad entre medio utilizado por el agresor y el usado por el que se defiende, véase: Sото (2005), p. 3.

35 Cobo del Rosal (2011), p. 126.

${ }^{36}$ ORTS Y GONZÁlez (2008), p. 175. 
de la legítima defensa ${ }^{37}$. La racionalidad del medio, según la doctrina ibérica, no implica una ponderación en clave aritmética de los mismos utilizados ${ }^{38}$, sino una ponderación de las posibilidades de defensa del individuo ${ }^{39}$. La aplicación de la proporcionalidad ha de ser un criterio complementario u accesorio al examen de las circunstancias específicas del caso. Ello, en cuanto es posible aplicar la defensa legítima en casos de desproporción evidente cuando el medio empleado sea prácticamente el único recurso que tiene el agredido a mano. Por otro lado, en cuanto en un momento de extrema tensión no se puede pedir al defensor que valore cabalmente las características del medio ofensivo y defensivo, o busque medios alternativos ${ }^{40}$, ni que deba correr riesgo ${ }^{41}$. Por ello, para parte de la doctrina es irrelevante la estricta proporcionalidad entre el mal causado con la defensa y el que amenazaba con la agresión ${ }^{42}$, incluso admitiendo la posibilidad de una gran desproporción entre ellos ${ }^{43}$.

De todo lo anterior se puede afirmar, entonces, que la defensa racional, para los efectos de la legítima defensa, es aquella que satisface la presencia de una necesidad abstracta y de una necesidad concreta de la defensa. Ahora, el problema se ha de situar, necesariamente, en la necesidad concreta de la defensa. Y, en este sentido, la necesidad concreta de la defensa se ha entendido

37 Morillas (2004), p. 239.

38 Cobo del Rosal (2011), p. 126; Matellanes (2010), p. 269; Luzón (2009), p. 121.

39 Quintero y Morales (2010), p. 535. Por ejemplo, para Orts y GonzÁlez (2008), p. 176, habría proporcionalidad entre el ataque con un palo de grandes dimensiones y con un clavo en la punta, empleado de forma letal, y el disparo con arma de fuego. No existe proporcionalidad objetiva entre el ataque con un palo de billar partido por la mitad y el uso de una navaja de once milímetros.

40 Matellanes (2010), p. 270, STS No 1.541/2005, de 21 de diciembre de 2005; López (2010), p. 649; MORILLAS (2004), p. 240; ZUGALdía (2010), p. 314.

${ }^{41}$ Roxin (1997), p. 629. Por su parte, Baldó (1994), p. 311, considera que "... por ejemplo, no es exigible recurrir a otros medios menos lesivos -óptica del agresor-cuando ello suponga una relevante disminución de las posibilidades de éxito de la defensa o cuando éstos no aseguren una rápida y definitiva evitación del peligro amenazante -óptica del defensor-".

${ }^{42}$ En este sentido, Dí́z (2011), p. 271; Luzón (2002), p. 881, considera que "no se exige en absoluto la proporcionalidad entre los bienes jurídicos, pues 'racional' no significa proporcional, de modo que la defensa puede, si es preciso, dañar bienes del agresor de mayor valor que los agredidos. Ello es lógico dado el doble fundamento de la eximente y su diferencia con el estado de necesidad, pues por la agresión ilegítima los bienes del agresor no están en pie de igualdad con los bienes jurídicos y el Derecho agredidos"; Luzón (2004), p. 411; Zugaldía (2010), p. 314; Welzel (1976), p. 103. En contra, Morillas (2004), p. 240; Rodríguez (2010), p. 146; Roxin (1997), p. 632.

${ }^{43}$ DíEz (2011), p. 271. El autor considera que la defensa puede ir todo lo lejos que sea necesario para impedir la lesión del bien jurídico y del ordenamiento jurídico. Por su parte, Baldó (1994), p. 310, considera que "Más allá de la 'necesidad racional del medio empleado para impedirla o repelerla', las reglas de la legítima defensa no imponen filtro posterior alguno que impida originar daños incluso mucho mayores que los que amenazan (!)". 
concurrente de acuerdo a un examen negativo: "siempre y cuando el medio empleado sea el menos lesivo para los efectos de defensa" ${ }^{\prime 4}$. Es posible encontrar en el tratado de Feuerbach (1801) alguna alusión al criterio del medio menos lesivo cuando se refiere a los requisitos de la defensa necesaria:

“V) El uso de la fuerza privada debe ser la única posibilidad de conservación del derecho. Por consiguiente, el agredido no debe haber podido contrarrestar la acción del agresor de otro modo que con la fuerza, en forma segura y sin perjuicio para otro derecho o bien; no debe haber sido posible al necesitado un medio de defensa inferior al empleado como medio suficiente para evitar el peligro" ${ }^{\prime 4}$.

Ahora, la construcción que hace el autor alemán de esta regla puede encontrar una cierta justificación en que para el mismo el fundamento de la legítima defensa se sitúa en la "subsidariedad" del ejercicio de la fuerza de parte de los ciudadanos siempre que la protección del Estado sea imposible ${ }^{46}$. Ello, en cuanto, como principio general, el ciudadano ha transferido al Estado su derecho al uso de la fuerza privada ${ }^{47}$. Si la legítima defensa es un ejercicio excepcional de retorno del uso de la fuerza privada transferida al Estado, entonces se entiende perfectamente que ella ha de ser lo más limitada posible y ha de recurrirse a ella a falta de cualquier otro medio menos lesivo.

En efecto, en Alemania se afirma que la acción defensiva debe ser necesaria, apta o idónea, y representar la respuesta de menor entidad frente al ataque. Roxin señala que "necesaria" es toda defensa idónea, que sea la más benigna de varias clases de defensas elegibles y que no esté unida al riesgo inmediato de sufrir un daño ${ }^{48}$. Wessels señala que la acción de defensa es necesaria cuando puede esperarse con seguridad la conclusión inmediata del ataque y garantiza de la mejor manera la eliminación definitiva del peligro ${ }^{49}$. En este sentido, el atacado debe emplear el medio menos lesivo de defensa ("das mildestes Mittel zur $\left.A b w e h r^{\prime \prime}\right)$. Es decir, aquel que con la misma eficacia ocasione el menor daño $0^{50}$,

\footnotetext{
44 En contra, Bullemore y Mackinnon (2005), p. 59.

45 Feuerbach (1989), p. 73.

46 Feuerbach (1989), p. 72.

47 Feuerbach (1989), p. 72.

48 Roxin (1997), p. 628.

49 Wessels (1980), p. 95.

50 Wessels y Beulke (2006), p. 107.
} 
el medio mínimo ${ }^{51}$ o aquel que comporta la perdida mínima para el agresor ${ }^{52}$ o sus bienes jurídicos ${ }^{53}$. Desde esta perspectiva, entre varias posibilidades de defensa igualmente eficaces, debe elegirse aquella que causa el daño menor ${ }^{54}$.

En este sentido, Roxin proporciona ejemplos de elección del medio más benigno de defensa: "quien pueda repeler al agresor con sus puños o a patadas, no puede echar mano al cuchillo o al revolver; y quien pueda intimidar al agresor amenazándolo con un arma contundente o de fuego o mediante disparo de advertencia, no puede disparar sin más" ${ }^{\prime \prime 5}$.

En este sentido, la defensa puede ir tan lejos como sea necesario para la defensa real de la agresión, pero no más allá de lo que sea absolutamente necesario para ello ${ }^{56}$. Sin embargo, la necesidad de la defensa no está vinculada a la proporcionalidad entre el daño causado y el impedido ${ }^{57}$. En efecto, la justificación de esta regla puede encontrarse en que la legítima defensa carece de carácter punitivo y únicamente sirve de protección de intereses amenazados ${ }^{58}$.

Por otro lado, el agredido tampoco está obligado a escoger, de entre varios medios disponibles, el más leve cuando este medio le supone, frente a otros, un esfuerzo o costo mayor ${ }^{59}$ o riesgo ${ }^{60}$.

Sobre la pregunta acerca de qué medios de defensa son eficaces para garantizar el cese inmediato de los ataques y eliminar el riesgo final, hay que tomar en consideración la fuerza del ataque, el peligro del agresor y los medios de defensa que están disponibles ${ }^{61}$. Aun cuando el agredido debe aplicar el medio mínimo, puede llegar incluso hasta la muerte si este es el último medio para la defensa ${ }^{62}$. Dependerá, en definitiva, de la fortaleza del autor y víctima, de las

\footnotetext{
51 Welzel (1976), p. 93.

52 JаKOBS (1997), p. 472.

53 Frister (2013), p. 223

54 Wessels (1980), p. 95; Jescheck (1981), p. 467; Stratenwerth (2005), p. 200.

55 Roxin (1997), p. 629.

56 Welzel (1976), p. 93.

57 Roxin (1997), p. 632; JESCHECK (1981), p. 467.

58 JeSCHECK (1981), p. 468.

59 Jakobs (1997), p. 473; WesSels (1980), pp. 95 y 96.

60 Roxin (1997), p. 629.

61 Wessels y Beulke (2006), p. 107.

62 Welzel (1976), p. 93; JaKobs (1997), p. 472.
} 
perspectivas de resultados y de los medios defensivos disponibles, no importando, incluso, la proporcionalidad de los medios afectados ${ }^{63}$.

En Italia, por su parte, la regla de opción del medio menos lesivo se articula sobre la base del concepto de "inevitabilità" de la defensa, en virtud de la cual no puede haber otro medio para evitar la ofensa excepto por medio del uso de la violencia. Ahora, la doctrina discute si el concepto de necesidad implica la necesidad de la defensa o si, por el contrario, se trata de conceptos sin una relación directa ${ }^{64}$. Por ejemplo, para Sarno y Sarno es posible todavía definir como necesaria una conducta defensiva "quando tale pericolo non risultava neutralizzabile mediante una condotta alternativa lecita" y "quando, infine, non poteva essere adottata una condotta meno lesiva di quella in concreta tenuta, parimenti idonea alla finalità difensiva e alla tutela dell'aggredito"65.

En los ordenamientos del common law, la regla de opción del medio menos lesivo se ha configurado sobre la base de la racionalidad de la defensa y de la máxima "lesser evil" (menor daño), cuya comparación en un primer momento ha considerado el daño prevenido y la fuerza defensiva, pero que un segundo momento la doctrina considera que debe estar referida a la fuerza de las vías alternativas de defensa disponible ${ }^{66}$. En un sentido similar al de Italia, se entiende que la necesidad cualitativa de la defensa implica que la agresión no se pueda prevenir de otra forma ${ }^{67}$. En este mismo sentido, la discusión ha estado moderada por el criterio "duty to retreat" (deber de retirada), que finalmente se ha estimado un elemento más para valorar la razonabilidad y necesidad del uso de la fuerza de la defensa (Inglaterra) ${ }^{68}$, teniendo mayor importancia en Estados Unidos como requisito previo al uso de la fuerza letal emanado de la acción defensiva (recogido en el Model Penal Code ${ }^{69}$ ), aunque no por ello menos cuestionado como criterio $^{70}$.

63 JAKOBS (1997), p. 472.

${ }^{64}$ BeLlini (2006), p. 102.

65 Sarno y Sarno (2008), p. 27.

${ }^{66}$ SANGERO (2006), p. 144.

67 SANGero (2006), p. 145.

${ }^{68}$ ElLiot y Quinn (2016), pp. 379 y 380.

${ }^{69}$ Véase Model Penal Code, art. 3.04 (2) (b) ii: (b) "The use of deadly force is not justifiable under this Section unless the actor believes that such force is necessary to protect himself against death, serious bodily injury, kidnapping or sexual intercourse compelled by force or threat; nor is it justifiable if: (ii) the actor knows that he can avoid the necessity of using such force with complete safety by retreating or by surrendering possession of a thing to a person asserting a claim of right thereto or by complying with a demand that he abstain from any action that he has no duty to take...".

70 SANGero (2006), p. 201. 
La doctrina nacional acepta que han de adoptarse otras posibilidades de defensa más expeditas, fáciles y con razonable seguridad de éxito frente a la defensa legítima en atención a la exigencia de necesidad racional del medio empleado $^{71}$. En este sentido, la necesariedad de la defensa exigiría, dadas las circunstancias, que el sujeto no disponga de otra forma menos enérgica de defenderse con éxito ${ }^{72}$. Sin embargo, otra parte de la doctrina considera que la necesidad de defenderse, como concepto esencial de la legítima defensa, precisa que esta sea imprescindible para repeler la agresión, por un lado, y la elección del medio menos lesivo en atención a la exigencia de racionalidad de los medios, por otro ${ }^{73}$.

En efecto, al parecer esta fue la opinión de la comisión redactora del CP chileno, en cuanto en la sesión $\mathrm{N}^{\circ} 120$ se puso de relevancia que la legítima defensa exigía también que no hubiera otro medio racional de impedir o repeler la agresión ${ }^{74}$.

La aplicación en caso concreto de esta regla que permite apreciar la legítima defensa va a depender de un juicio de ponderación del medio y su lesividad respecto de la afectación de los bienes jurídicos del agresor. Y, a su vez, la validez de dicha afectación dependerá de que efectivamente por medio de ella se pueda repeler o impedir la agresión. Piénsese que la legítima defensa, aunque parezca baladí, es la defensa jurídicamente configurada de un derecho concretamente agredido ${ }^{75}$.

Desde esta perspectiva, en principio, este juicio de ponderación es un juicio racional y, como tal, presupone la presencia de ciertas condiciones en donde se desenvuelva la decisión defensiva de parte de la víctima de la agresión. La pregunta que subyace a la apreciación de este criterio es si en el juicio de ponderación ha de tener alguna importancia el bien jurídico que se afecta o pone en peligro por la agresión. Al parecer, en principio, la respuesta sería negativa, porque solo importa la mayor o menor afectación de los bienes jurídicos del agresor y los medios que utilice para ello ${ }^{76}$. Ninguna importancia tendría para

71 EtCheberRy (1997), p. 256.

72 Cury (2005), p. 375.

73 GaRRIDO (2003), p. 133.

${ }^{74}$ Véase EtCheberRy (1997), p. 255.

75 KINDHÄUSER (2013), p. 78.

${ }^{76}$ Ello, por supuesto, es distinto en el supuesto de la legítima defensa privilegiada del artículo $10 \mathrm{~N}^{\circ} 6$, inciso segundo, del $\mathrm{CP}$, donde se acepta la presunción de los requisitos de los $\mathrm{N}^{\circ} \mathrm{s}$. 4 y 5, precedentes: "cualquiera sea el daño que se ocasione al agresor". Por ello, ex profeso se ha excluido la legítima defensa privilegiada del análisis del presente trabajo, por presentar singularidades que ameritan un desarrollo propio e independiente que no es posible llevar acabo en este lugar. 
apreciar la necesidad concreta de la defensa el bien jurídico afectado o puesto en peligro por la agresión ${ }^{77}$, de momento que, en principio, ya fue valorado en el juicio de la necesidad abstracta de la defensa. Sin embargo, aunque se hable de necesidad concreta de la defensa, para ponderar la menor lesividad del medio que se escoja tendrá importancia, aunque sea de manera indirecta, el bien jurídico potencialmente afectado por dicha elección, lo cual evidencia que no es completamente ajena a la necesidad concreta de la defensa una cierta ponderación de intereses en juego.

\section{Las condicionantes de la elección del medio menos lesivo (I): Las consecuencias de la reacción neurobiológica ante el estrés de la agresión ilegítima}

Para analizar los alcances de la regla de opción del medio menos lesivo creo que resulta importante desarrollar brevemente cuáles son las reacciones fisiológicas o neurobiológicas que se presentan en una persona cuando se enfrenta a una situación de riesgo que le genera tensión o estrés. Ello, en cuanto nos permitirá construir el escenario en donde se sitúa la víctima de una agresión ilegítima. Por otro lado, también se hará referencia a cómo los sujetos, ex post, toman decisiones bajo peligro.

Si bien no ha habido un desarrollo desde el punto de vista de las ciencias empíricas en sentido estricto de parte de la doctrina penal nacional respecto de las condiciones de aquellos que repelen una agresión, lo cierto es que sí es posible apreciar determinados acercamientos basados en la experiencia y en el sentido común. Por ejemplo, parte de la doctrina ha señalado que no es razonable esperar de quien es agredido un razonamiento sereno y objetivo de la situación ${ }^{78}$. Por otro lado, se considera que para apreciar la necesidad racional del medio uno ha de situarse "en el lugar del sujeto que se defendió y en el momento de la agresión" ${ }^{\prime 79}$.

\subsection{La reacción del organismo ante sucesos de estrés}

La legítima defensa presupone que el agredido se encuentre en una situación de peligro o afectación de sus bienes jurídicos de la cual se defiende. Solo si el sujeto amenazado identifica la situación de peligro, entonces podrá hacerle frente con una acción defensiva. Sin embargo, esta operación de

\footnotetext{
77 En este sentido, Politoff y Matus (2002), p. 131, aunque precisan que ha de respetar los límites de proporcionalidad y racionalidad.

78 Bullemore y Mackinnon (2005), p. 59.

${ }^{79}$ GarRido (2003), p. 133.
} 
categorización cognitiva no solo es el presupuesto para la existencia de una defensa, sino también es la "llave" que abre el grifo para que el organismo se adapte al tránsito desde una situación de neutralidad o no peligro (previo a la agresión) a un estado de amenaza o peligro de sus bienes jurídicos, posterior al inicio de la agresión ilegítima. Ello tiene su correspondencia "neurobiológica", de momento que, identificado el peligro, se desencadena una serie de sucesos y reacciones químicas que tienen por objeto preparar al organismo para una reacción de "ataque o huida" como una forma adaptativa del ser humano para hacer frente a los peligros y que ha permitido la supervivencia de la especie humana hasta nuestros días.

Ante una situación de estrés, el organismo genera una serie de reacciones fisiológicas que suponen la operatividad del eje hipofisosuprarrenal (HSP) y del sistema nervioso vegetativo (SNV). Ambos sistemas, ante un evento peligroso, proceden a la liberación de hormonas que, transportadas a través de la sangre, excitan, inhiben o regulan la actividad de los órganos ${ }^{80}$.

El HSP, ante agresiones físicas, por ejemplo, reacciona secretando el hipotálamo una hormona liberadora de corticotropina. Esta genera una reacción en las glándulas suprarrenales que se traduce en la producción de corticoides que pasan al torrente sanguíneo, que aumentan el nivel de glucosa en la sangre, incrementando tanto la fuerza como la intensidad de la actividad muscular, etc.

El SNV, en iguales circunstancias, reacciona secretando catecolaminas, como la adrenalina y la noradrenalina. Estas hormonas son las encargadas de poner el cuerpo en estado de alerta a fin de prepararlo para luchar o huir. De esta forma, por la acción de estas sustancias es posible constatar una dilatación de las pupilas, dilatación bronquial, aumento de la coagulación, incremento del ritmo cardiaco, vasodilatación muscular y vasoconstricción cutánea, incremento de la producción de tiroxina que favorece el metabolismo energético, la síntesis de proteínas, etc.

En sentido estricto, técnico y más actual el estrés es una respuesta adaptativa presente en toda la escala mamífera que permite al organismo enfrentar eventos físicos y/o psíquicos que amenazan la homeostasis del medio interno ${ }^{81}$. Estos eventos forman parte de la respuesta de "lucha o huida" ${ }^{22}$, cuyo sentido

\footnotetext{
${ }^{80}$ Para una explicación más técnica de los efectos biológicos del estrés en el cuerpo, véase KUDIELKA y KirSChBAum (2007), pp. 3 y ss.

${ }^{81}$ Chrousos y Gold (1992), pp. 1244 y ss. Para una mayor explicación sobre las fases del síndrome de adaptación general, véase SeLYe (1937), pp. 169 y ss.

82 Mcewen (2008), pp. 174 y ss.
} 
adaptativo principal es movilizar y disponer de energía suficiente para cubrir las demandas requeridas por el organismo ${ }^{83}$.

He querido traer a colación las reacciones fisiológicas del cuerpo ante situaciones de estrés como una forma de contextualizar el escenario que tiene la víctima de una agresión ilegítima para tomar decisiones referidas a la defensa. Es decir, cuando se habla de racionalidad de la defensa -y como la elección del medio menos lesivo es importante para su apreciación-, se debe pensar que la puesta en peligro para los bienes jurídicos del agredido genera un estado de alarma en el sentido neurobiológico, producto de la categorización de la agresión como "peligrosa". Desde esta perspectiva, los criterios de racionalidad de la defensa operan en este estado de alarma. Por ello, de entrada, aparece excesivo exigir una racionalidad de la defensa cuando las condiciones neurobiológicas (no dependientes de la voluntad de la víctima) son inconvenientes para la aplicación de los distintos criterios que tanto la doctrina como la jurisprudencia aceptan que moderan la procedencia de esta causal de justificación.

El $\S 33$ del StGB, denominado exceso de la legítima defensa, señala que si el autor excede los límites de la legítima defensa por confusión, temor o miedo, entonces no será castigado. Para Welzel, se corresponde con una situación de exceso intensivo de la legítima defensa ${ }^{84}$, aunque para Jakobs también quedaría incluida la defensa que tiene lugar en estado pasional asténico previo o posterior a la actualidad del ataque (exceso extensivo) ${ }^{85}$. Si bien parte de la doctrina alemana reconoce que en ello hay una formulación neutra, no existiendo en ello un pronunciamiento respecto de la naturaleza jurídica del precepto (causal de justificación, eximente de culpabilidad o de exclusión de la punibilidad), lo cierto es que el legislador no quiso inmiscuirse sin necesidad en una disputa teórica ${ }^{86}$. Para Roxin se trataría de una causa de exculpación en el sentido habitual del lenguaje, en virtud de la cual el sujeto que se excede se comporta culpablemente, aunque sea de manera reducida ${ }^{87}$. Según el mismo autor, la extralimitación de la legítima defensa impune por este apartado solo se extendería a la causada por estado pasionales asténicos (procedentes de la debilidad), excluyéndose aquellas acciones defensivas derivadas de estados pasionales esténicos (procedentes de fuerza o vigor), como la cólera o la ira, la

\footnotetext{
83 BuCKIGHAM (2006), pp. 258 y ss.

${ }^{84}$ Welzel (1987), p. 129.

85 JAKOBS (1997), p. 707.

${ }^{86}$ Roxin (1997), p. 927.

${ }^{87}$ En el mismo sentido, JAKOBS (1997), p. 705, considera que el exceso en la legítima defensa hace decaer la culpabilidad por falta de exigibilidad.
} 
indignación o la furia combativa (afán de lucha o ganas de pelea) ${ }^{88}$. En efecto, la impunidad del exceso de la legítima defensa se explica mayoritariamente por una doble reducción de la culpabilidad: la derivada del estado pasional y la emanada de una acción de defensa que rechaza una agresión ilegítima ${ }^{89}$. En este mismo sentido, frente a la neutralidad del legislador, la jurisprudencia alemana de posguerra mayoritaria la considera una exculpación ${ }^{90}$.

EI § 33 del StGB aparece, primeramente, como una buena solución de lege ferenda y da fuerza a la necesidad de otorgar alguna importancia a ciertas condiciones psicológicas del defensor en situación de defensa legítima. Sin embargo, implícitamente reconoce que ellas solo son cuestiones de culpabilidad y de ocurrencia particular (dependiendo del caso), ratificando con ello la generalidad de un estado de normalidad incompatible con estados asténicos que permitan en casos excepcionales la exculpación. Por mi parte, considero que hay buenas razones para sostener que las reacciones del organismo frente al estrés de la agresión son condiciones generales o generalizables a todos los ciudadanos, que exceden el marco de la imputación personal, por lo que su análisis podría tener mejor asidero en el nivel de la antijuridicidad por vincularse estrechamente con alguna vertiente de ese "injusto objetivo para todos" referido a las condiciones implícitas del antecedente de la norma. Lo que quiero decir es que, en ciertos supuestos identificables y generalizables, ese estado de "normalidad" que permita optar por el medio menos lesivo no existe ni es exigible. A este respecto, Baldó considera que el deber de solidaridad mínimo exigible en la defensa necesaria, que se traduce en la aplicación del criterio de la opción por el medio de defensa menos lesivo, no compromete intereses esenciales del agredido como la vida, integridad física o salud ${ }^{92}$. Ello trae como consecuencia que el criterio del medio menos lesivo no opera para moderar la defensa cuando lo amenazado sea un bien vital o de gran importancia, como la salud o la integridad física, lo que también manifiesta una cierta derrotabilidad del criterio en estos casos.

Así, entonces, a mi modo de ver, los criterios que dicen relación con exigencias de procesos cognitivos que presuponen un contexto somático normal no pueden ser utilizados como criterios de inferencia, generalización o regla de la racionalidad de la defensa o de algún otro aspecto que influya en la defensa necesaria.

\footnotetext{
${ }_{88}$ Roxin (1997), p. 927; también JAKOBS (1997), p. 706.

89 Roxin (1997), p. 927

90 Roxin (1997), p. 930.

91 BALDó (2016), p. 454.

92 BALDÓ (2016), p. 457.
} 
Por el contrario, en estas situaciones de peligro o estrés el contexto donde un individuo debe tomar una opción de defensa ante una agresión modera dicha decisión, aunque no la condiciona completamente. Así, es posible evidenciar una contradicción entre las condiciones presupuestas por la regla de opción del medio menos lesivo y lo que ocurre en el caso de amenazas vitales, por ejemplo.

En otro sentido, el reconocimiento de la regla de opción del medio menos lesivo implicaría privilegiar reconociendo la posibilidad de justificación por medio de la legítima defensa a quienes poseen ciertas características biológicas no dependientes de su voluntad, frente a quienes neurobiológicamente generan una reacción más intensa ante los sucesos peligrosos, como lo es la agresión ilegítima.

En este sentido, tomando en consideración las reacciones neurobiológicas del ser humano frente a sucesos de peligro, parece al menos difícil que ellas sean compatibles con la operación racional de elección del medio menos lesivo frente a agresiones ilegítimas y ello precisamente funda una inconsistencia para que dicho criterio sea aplicado con carácter general a todos los casos de legítimas defensas, sin precisar circunstancias específicas, concretas y particulares de cada caso. De hecho, las reacciones neurobiológicas frente al estrés (como el que genera la agresión) no es una circunstancia particular, sino general, presente en todos los seres humanos, pues se trata de un mecanismo adaptativo. Lo que puede llegar a presentar cierta variación es la intensidad de los efectos de dicha reacción en el organismo de los sujetos. Por ello, los criterios correctores que atienden a las circunstancias particulares del caso en concreto, las condiciones de la víctima o las características de la agresión no son del todo satisfactorias, porque no se trata de "particularidades" de un caso en concreto, sino de considerar la "generalidad" de la reacción adaptativa frente al estrés, presente en todos los seres humanos.

\subsection{Las condicionantes de la elección del medio menos lesivo (II): Las decisiones bajo presión y estrés}

Ahora, resulta pertinente, para cuestionar la eficacia de la regla, preguntarse si ex post los sujetos suelen emplear criterios racionales, como el de elección del medio menos lesivo, cuando tienen que tomar decisiones frente a fenómenos peligrosos de la cual dependa la vida propia o de terceros a su cargo.

Si retomamos algunos conceptos de la psicología del pensamiento y entendemos que la decisión se basa, entre otras cosas, en la administración de la información que se posee en la memoria, como base de datos, debemos tener presente que por las limitaciones de la mente humana los individuos buscarán 
simplificar sus decisiones ${ }^{93}$. Es decir, esto implica un proceso de descarte de hipótesis de conceptos, recuperación de información que facilite la conceptualización o el razonamiento analógico, etc. Pues bien, en este sentido, la decisión del ejercicio de un deber de retirada o de la elección de un medio menos lesivo es una resolución sobre el actuar que contiene una gran carga cognitiva, distinta a otras decisiones cotidianas menos complejas.

Con mayor razón aún, la complejidad de la decisión impide hacer estas exigencias a las personas que ven amenazados bienes jurídicos de gran valor. Los criterios que establece la doctrina y la jurisprudencia, a partir de una valoración ex ante de las circunstancias del caso, nos parecen de una excesiva dificultad para que pueda ser ejercidos, y más aún, exigibles a una persona que se defiende legítimamente. Es decir, la configuración de estos elementos atenta contra la tendencia natural de las personas de simplificar la toma de decisión a partir de la facilidad del manejo del conocimiento que se tiene del ambiente en que se dan estos actos. Desde esta perspectiva, en palabras más sencillas, el arsenal dogmático y jurisprudencial respecto del ejercicio del deber de elección del medio menos lesivo atenta contra la capacidad natural de simplificar o reducir la información para tomar una decisión. Así, la persona que se defiende se ve sometida a la exigencia de una gran carga cognitiva por parte de quienes entienden la racionalidad de la defensa como opción del medio menos gravoso, por un lado, y a la reducción de la misma carga cognitiva de la decisión como mecanismo adaptativo, por otro. Ello impide que la opción del medio menos lesivo sea considerada un requisito ontológico de la racionalidad defensiva, porque no puede ser completamente racional optar por algo que la naturaleza dificulta. Más bien lo contrario. Así, es posible evidenciar una segunda contradicción entre la regla de opción del medio menos lesivo y el presupuesto en que se basa el RPD. El segundo nos indica que una situación de peligro los seres humanos buscamos simplificar cognitivamente las decisiones que debemos tomar en dicho contexto; sin embargo, la racionalidad de la decisión sobre la opción por el medio menos lesivo eleva la complejidad de la operación cognitiva en dicho contexto.

Dentro de la psicología, Gary Klein ha planteado un esquema de razonamiento a partir del estudio de las decisiones bajo estrés o condiciones de presión ${ }^{94}$. En efecto, este autor estudió cómo los jefes de bomberos ("commander's firefighter") tomaban sus decisiones bajo presión o riesgo, especialmente en el

93 Véase Garnham y OakHill (1996), p. 289, donde se cita a la minimización de la carga cognitiva como uno de los déficits del pensamiento cotidiano según Perkins; Nieva (2010), p. 127.

${ }^{94}$ Klein (1998), pp. 7 y ss. También en Klein (2008), pp. 456 y ss. 
operativo de combate de incendio donde eventualmente existía riesgo para las personas (bomberos o moradores).

Las conclusiones a las que llega Klein es que tanto los comandantes de bomberos como los comandantes del ejército utilizan lo que él ha llamado un modelo de decisión de reconocimiento primario ("recognitional-primed decision making model", en adelante RPD) para la toma de decisiones en circunstancias de peligro. En efecto, cuando Klein realizó sus estudios, pretendía comprobar la hipótesis de que los comandantes efectuaban una selección de dos hipótesis intuitivamente más fuertes por medio del procedimiento de la comparación racional. Sin embargo, se dio cuenta de que los comandantes no efectuaban un proceso de decisión en el sentido clásico, sino que, por las condiciones especiales del contexto, utilizaban otro tipo de procedimiento, más eficaz ${ }^{95}$. En efecto, los comandantes usaban el RPD, que está compuesto principalmente por dos elementos. El primero, que podríamos considerar como prototipo, y el segundo, el constituido por un proceso de analogía y valoración del curso de acción.

De esta forma, los comandantes, cuando se enfrentaban a una situación de peligro y tenían que tomar algún tipo de decisión, lo primero que hacían era preguntarse si dicha situación les era o no familiar con relación a alguna otra de su experiencia (prototipo). Si esta situación era familiar, entonces el prototipo aplicado a dicho peligro indicaba un curso de acción que los comandantes evaluaban a través de una representación, simulación mental o imaginación del mismo, a fin de ordenar o no dicho curso de acción. A partir de la familiaridad de la situación, analizaban qué tipo de objetivos del prototipo tenía sentido respecto de la situación particular ("plausibles goals"); qué señales son o no importantes para proporcionar información sobre el caso ("cues"); las expectativas presentes y futuras de la situación ("expentancies"), y la acción típica que se tomaban esos casos ("typical action"). Con estos cuatro elementos se determinaba el curso de acción a seguir.

El RPD permite una agilidad en la determinación, pero puede llegar a ser falible. En efecto, es posible que para efectuar el diagnóstico de la situación sea necesario requerir más información. Por otro lado, es posible que la persona realice un diagnóstico errado sobre lo cual se va a percatar cuando vea que sus expectativas no se han cumplido. En otro sentido, como es un método que se basa principalmente en la experiencia o en la representación de modelos

95 KLEIN (1998), p. 11, lo expresa de esta forma: "The commanders did not consider two. In fact, they did not seem to be comparing any options at all. This was disconcerting, and we discovered it at the first background discussion we had with a fireground commander, even before the real interviews. We asked the commander to tell us about some difficult decisions ha had made. 'I don't make decisions' he announced to his startled listeners. 'I don't remember when I've ever made a decision'". 
mentales, las decisiones serán tomadas conforme a ellos, siendo muy difícil el empleo de criterios de pertinencia, porque no se tiene el tiempo para recuperarlos a través de un proceso más complejo de razonamiento.

Después de todo lo anotado respecto de las decisiones bajo estrés y el RPD, veamos qué consecuencias tiene confrontar este modelo con la elección del medio menos lesivo en la defensa legítima. En primer lugar, el mecanismo del RPD ejemplifica que las personas sometidas a presión o estrés buscan simplificar el acervo cognitivo de información disponible para tomar la mejor decisión posible. Esta disminución, a priori, se muestra incompatible con una operación racional que incluya la ponderación de la elección del medio menos lesivo. Se vuelve a mostrar aquí la inconsistencia de la regla de opción de medio menos lesivo basada en la contradicción que supone por su exigencia de una toma de decisión compleja en un contexto de peligro.

Pero si todo esto no fuera suficiente para demostrar que la exigencia de escoger el medio menos lesivo es un criterio jurídico inconsistente, solo basta recurrir a la dificultad que existe para tomar una decisión adecuada en situaciones peligrosas o de estrés ${ }^{96}$. De otro lado, las reacciones neurobiológicas de quien se ve sometido al peligro hacen imposible estimar de manera general la posibilidad de efectuar una reflexión seria y fría acerca de la elección racional del medio menos lesivo, atribuyendo circunstancias negativas cuando ello no ocurre.

En este sentido, por ejemplo, el TS español ha considerado respecto de la evaluación de la racionalidad de la defensa que "... más que la semejanza material de los instrumentos o armas empleados debe ponderarse la efectiva situación en que se encuentran el agresor y agredido, en la que puede jugar el estado anímico del agredido y la perturbación que en su raciocinio sobre la adecuación del medio defensivo empleado pueda causar el riesgo a que se ve sometido por la agresión" ${ }^{\prime \prime 7}$.

Finalmente, como bien lo expresa Klein, la intuición depende del uso de la experiencia para reconocer los patrones claves que indican la dinámica de la situación ${ }^{98}$.

Ahora, llevado esto al plano que nos convoca, la situación de la víctima que se defiende está sometida a una situación de peligro de forma análoga a la que presentan los sujetos que ha estudiado Klein. Y, desde esta perspectiva, es altamente probable que la víctima sometida a legítima defensa aplique ex post

\footnotetext{
96 KleIN (1998), p. 78.

97 STS No 962/2005, de 22 de julio de 2005, FJ $3^{\circ}$.

98 KLEIN (1998), p. 31.
} 
el proceso de RPD para defenderse, sobre todo cuando se vean amenazados bienes jurídicos de muy importante valor, como el de la vida, precisamente porque la situación de peligro generará una necesidad de optimizar recursos en el momento. Así, aunque el estudio de Klein solo nos puede otorgar ciertas "luces" aplicables analógicamente a la situación que experimenta una víctima sometida a una agresión ilegítima, descarta notoriamente que las personas sometidas a presión o estrés empleen un modelo racional y lógico para decidir, lo que parece asumir la jurisprudencia y la doctrina cuando afirman que es posible y exigible que la víctima sometida a una agresión ilegítima opte por el medio menos lesivo para su defensa. Es decir, la regla de opción del medio menos lesivo tampoco puede fundarse en una práctica generalizada de las personas sobre las decisiones frente situaciones de estrés como la que genera la agresión. Ello indudablemente aumenta la inconsistencia del criterio por déficit en su operatividad.

\section{Vocación descriptiva de la regla de elección del medio menos lesivo}

En este punto surge la pregunta del por qué podría haberse formulado el criterio de adopción del medio menos lesivo como baremo de la racionalidad de la defensa. En efecto, el enunciado normativo "necesidad racional de la defensa", contemplado como requisito de la legítima defensa, presenta amplios márgenes interpretativos, que deben ser dotados de contenido. Es decir, la defensa racional y necesaria como requisito de la legítima defensa es un concepto vago, que ha de ser precisado para ser aplicado a casos en particular. Este proceso conlleva una operación de construcción de "géneros" de casos que contengan propiedades identificables. Es decir, la defensa necesaria se dota de contenido a partir de un proceso de generalización acerca de sucesos que ocurren en el mundo. Solo de esta forma el enunciado "defensa racional y necesaria" puede presentar una funcionalidad comunicativa.

Schauer considera que la existencia de una regla descriptiva implica necesariamente generalizar. No existen reglas para casos particulares. Aunque no es el lugar para entrar a la distinción entre reglas descriptivas y prescriptivas, lo cierto es que ambos tipos de reglas se dirigen a tipos, y no a casos particulares ${ }^{99}$. La generalización, por su parte, es una operación cognitiva de categorización, como una forma de entender mejor el mundo que nos rodea y extraer propiedades de los objetos. De esta forma nos adaptamos mejor al ambiente y podemos establecer inferencias de los sucesos del mundo y comportarnos de acuerdo a ello. Y en este sentido, por ejemplo, las generalizaciones que un hablante elige entre las numerosas disponibles, suprimen diferencias

99 Schauer (2004), p. 76. 
que habrían sido destacadas por otros, del mismo modo que la generalización elegida evocará semejanzas que habrían sido soslayadas por sujetos diferentes.

Pues bien, la generalización no es algo exclusivo de la psicología o de la epistemología, sino que las normas jurídicas, en cuanto expresión del lenguaje, también se valen de la generalización como medio de prescripción ${ }^{100}$. En efecto, establecer cualquier regla supone el uso de una generalización elegida entre numerosas candidatas lógicamente equivalentes ${ }^{101}$. Así, la generalización prescriptiva comienza habitualmente con un caso que se toma como ejemplo de una categoría más general, y luego se busca la propiedad que es esencial o causalmente relevante para la concurrencia de la categoría más general en virtud de la cual se prescribe, que constituye la justificación de la norma para Schauer ${ }^{102}$. De esta forma, la justificación, como categoría más general, constituye el mal que se pretende erradicar o la meta que se pretende lograr ${ }^{103}$.

Lo importante de la justificación es que el predicado fáctico de una norma representa un conjunto de hechos que se hallan en una relación de causalidad probabilística con la justificación ${ }^{104}$, cuya prohibición efectiva disminuirá consecuentemente la probabilidad de la realización del mal contra el cual la regla va dirigida ${ }^{105}$.

La importancia de todo ello, y sin entrar en demasía en la cuestión, es que cuando se usa en una generalización imprecisa en el enunciado fáctico de la norma, se pueden producir resultados distintos de aquellos que serían indicados por la aplicación directa de la justificación que subyace a la generalización. Ello, no solo por las propiedades de vaguedad del lenguaje ${ }^{106}$, sino también -dada la imperfección del conocimiento- por la "falsabilidad" de la relación causal probabilística ${ }^{107}$ que subyace a toda generalización. Por ello se dice que la más precisa de las reglas es potencialmente imprecisa ${ }^{108}$.

\footnotetext{
100 Schauer (2004), p. 80.

101 SChauer (2004), p. 83.

102 SChauer (2004), p. 84.

103 Schauer (2004), p. 84.

104 SChauer (2004), p. 87.

105 SChauer (2004), p. 89.

106 Véase Waismann (1945), pp. 123 y ss.; Guastini (2014), p. 68; Endicott (2006), p. 264; Hart (1998), pp. 15 y ss.; DWORKIN (1989), p. 87; KaufMAnN (1997), p. 47, donde constata la ambigüedad de la palabra "norma".

107 Como afirma Schauer, es posible constatar este fenómeno de inestabilidad incluso respecto de las reglas que hoy en día parecen no ser ni sub- ni sobreincluyentes respecto de sus justificaciones subyacentes.

108 SChauer (2004), p. 94.
} 
En el caso comentado, la generalización contenida en el criterio de opción del medio menos lesivo (si "se opta por el medio menos lesivo", entonces "hay defensa racional y necesaria") tiene un carácter impreciso que, frente a los estudios de las decisiones de las personas bajo presión o estrés, presenta baja corroboración empírica y, perfectamente, puede ser tenida como una generalización débil o espuria ${ }^{109}$. Con ello se quiere decir que la regla de opción de medio menos lesivo recoge casos que no necesariamente son una causa de una defensa racional y necesaria.

En este sentido, el criterio de la RPD antes explicado es un ejemplo de que, en la práctica, las defensas necesarias no se realizan únicamente por medio de la elección del medio menos lesivo. A lo anterior se debe agregar ciertas contingencias derivadas de la especialidad de ciertas características de quien ejerce la defensa que ahondan más profundamente en los problemas de vocación descriptiva de la regla del medio menos lesivo. Como pone de manifiesto Villegas, en los casos en que la mujer maltratada se defiende, generalmente se invoca por los tribunales el exceso en la defensa o la desproporción ${ }^{110}$. En este sentido, se olvida que la mujer, por sus diferencias físicas, siempre deberá acudir a un medio más peligroso ${ }^{111}$ si realmente asumimos que el defensor no está obligado a poner en riesgo la efectividad de la acción defensiva con tal de escoger un medio de defensa racionalmente adecuado. Lo anterior a todas luces es incompatible con la exigibilidad de la regla de la opción por el medio menos lesivo de defensa.

Es decir, el criterio de opción del medio menos lesivo, confrontado con los estudios de RPD, genera problemas de subinclusividad o infrainclusividad de situaciones que pueden ser consideradas defensa necesaria, pero que no se realizan sobre la base de la opción del medio menos lesivo. Si estamos en lo correcto, entonces, el criterio de la opción del medio menos lesivo, desde su arista descriptiva, no es una buena generalización para dar cuenta del concepto de "defensa necesaria". No cumple con una función totalizadora de descripción de la realidad de las situaciones de defensa como respuesta a la agresión ilegítima. Pareciere ser, entonces, que muy plausiblemente el criterio de la opción del medio menos lesivo como requisito de la racionalidad de la defensa se construye sobre la base de intuiciones que se han integrado en una regla con vocación prescriptiva, lo que, una vez más, puede cuestionar la consistencia del criterio.

109 Sobre el concepto de generalización espuria, véase TARUFFO (2009), pp. 444 y ss.

110 Villegas (2010), p. 150.

111 Villegas (2010), p. 150. 


\section{La regla "debe implica puede": La elección del medio menos lesivo como posible norma espuria}

Suele asociarse a la ética de Kant la formulación de la idea de que "debe implica puede"112. Con esta idea se alude a que, por ejemplo, la prohibición de una norma ha de poder ser realizada por los destinatarios. Desde esta perspectiva, si el legislador impone lo imposible, se comportaría irracionalmente, de momento que su deseo no ha de poder ser realizado"13. Así, entonces, "debe implica puede" es una máxima del legislador racional o razonable, a partir de la cual solo cosas (acciones) posibles deben ser objeto de normas ${ }^{114}$. En este sentido, el concepto de racionalidad del legislador incluiría restricciones más fuertes, como la exigencia de que los contenidos normativos sean no solamente consistentes (ejecutables), sino también que describan estados de cosas cuya realización sea física o humanamente posible ${ }^{115}$. En este mismo sentido, por ejemplo, Gardner considera que no pueden haber razones guía a favor o en contra de lo que no se puede hacer (de allí la proposición "deber implica poder") ${ }^{116}$.

Según V. Wright, el término "puede" de la máxima, si se interpreta como estipulación de la condición (lógica) para la existencia de las normas, se refiere a la habilidad humana. Es decir, como destreza necesaria para hacer dicha cosa, de forma que una persona puede hacer un determinado acto cuando en la mayoría de ocasiones de hacerlo lo conseguirá ${ }^{117}$. De esta forma, la habilidad de actuar es un presupuesto de la norma ${ }^{118}$.

V. Wright se vale de un ejemplo para explicar la cuestión: un oficial ordena a un soldado que atraviese un río a nado. El soldado se niega a meterse al agua, dando como excusa que no puede atravesar el río porque no sabe nadar. ¿Ha desobedecido la orden el soldado? En este sentido, el soldado solo podrá recibir un castigo por algo que haya podido hacer y que no hizo. Y como en este caso el soldado no puede hacer lo que la orden de atravesar el río a nado exige, no puede ser castigado por haber desobedecido esta orden. Es decir, el soldado no puede haber desobedecido la orden, porque solo hay lugar para la desobediencia cuando la obediencia es posible. "Y la obediencia es posible

\footnotetext{
112 V. WRIGHT (1979), p. 123.

113 V. WRIGHT (1997), p. 95.

114 V. WRIGHT (1997), p. 95.

115 MaranhaO (2016), p. 69.

116 Gardner (2012), p. 115.

117 V. WRIGHT (1979), p. 67.

118 V. WRIGHT (1979), p. 126.
} 
solamente cuando hay habilidad de hacer lo que se exige ${ }^{\prime \prime 19}$. Así, si se admite que el deber entraña habilidad, entonces, modus tollens del hecho que algo no puede hacerse, puede concluirse que no existe el deber de hacer este algo ${ }^{120}$.

Con relación al caso en análisis, especialmente las reacciones neurobiológicas de los seres humanos ante el estrés o peligro que puede generar una agresión ilegítima (especialmente en los casos de amenaza vital), muestra que la regla de opción del medio menos lesivo no cumple con la máxima "debe implica puede", porque las reacciones del organismo dificultan o impiden optar por el medio menos lesivo para defenderse. En términos de Von Wright, una gran porción de seres humanos no contaría con la "habilidad" para optar por un medio menos lesivo debido a las reacciones naturales del organismo frente a fenómenos de presión o estrés. Ahora, el análisis de esta observación, aunque sin desconocer la importancia de las características personales de quien se defiende, es una crítica a las condiciones generales de operatividad recogidas por la regla, más allá de un caso particular o de otro. Porque lo cierto es que todos los seres humanos contamos con una reacción neurobiológica ante los peligros como mecanismo de adaptación natural al entorno, circunstancia que no ha sido considerada por la regla de elección del medio menos lesivo. En efecto, con ello se privilegia (otorgando justificación) a quienes por diversas razones no dependientes de su voluntad o de su actuar presentan una reacción neurobiológica más atenuada ante al estrés de la agresión, frente a otros (la mayoría) en que el despliegue de la reacción es mucho más intenso. Precisamente, en este último caso, aquellos que frente a una agresión "deben" optar por el medio menos lesivo no "pueden" hacerlo.

En un sentido bastante similar, vinculado a las habilidades, Stratenwerth señala que para determinar el medio de defensa más leve también tienen que importar las capacidades del defensor. En efecto, señala que si "él es un mal tirador, y disparar a dar constituye la única posibilidad de defensa, todos los riesgos vinculados inevitablemente al disparo (hasta llegar al del homicidio) estarán cubiertos por la legítima defensa, aun cuando, de por sí, habría bastado con una lesión relativamente pequeña ${ }^{\prime \prime 21}$. Lo interesante de esta posición no es solo que vincula las capacidades del defensor con la aplicación de la regla, sino que indirectamente ratifica la posición que la capacidad o habilidad del defensor puede ser una cuestión a ser valorada en sede de juicio de antijuridicidad.

119 V. WRIGHT (1979), p. 130.

${ }^{120}$ V. WRIGHT (1979), p. 125.

121 Stratenwerth (2005), p. 200. 
Todo lo anterior permite entender por qué no es satisfactoria la reconducción de estos casos al juicio de culpabilidad. A este respecto, como señala Wessels, debe recordarse que para el juicio de culpabilidad el punto de referencia es la acción injusta, entendida como "culpabilidad de acto aislado". Así, culpabilidad significa reprochabilidad del hecho con respecto al sentimiento jurídicamente reprobable revelado en él ${ }^{122}$.

En efecto, en dicha sede se parte de la base de que, siendo posible el cumplimiento del deber, esto no se lleva a cabo por alguna excusa atendida a las circunstancias personales del sujeto. Sin embargo, en las situaciones analizadas, no es posible cumplir lo debido, en lo general, más allá de las particularidades del caso, pues es la regla de opción del medio menos lesivo la que presenta un déficit en las condiciones generales de operatividad, más allá de las condiciones personales del sujeto para ser conminado por la norma penal.

Indirectamente, lo anterior puede ser apoyado con la débil vocación descriptiva de la regla, a la cual hacía referencia en el apartado precedente. En efecto, los sujetos, frente al estrés de la agresión, no solo no pueden elegir el medio menos lesivo, sino que el mecanismo RPD muestra que en la práctica los sujetos tampoco suelen optar por el medio menos lesivo frente a fenómenos intensos de peligro, más allá de las condiciones de operatividad recogidas por la regla.

En definitiva, siguiendo a V. Wright, quienes debido a su reacción neurobiológica no pueden optar por el medio menos lesivo, entonces no "deben" optar por el medio menos lesivo, no debiendo ser ello un impedimento para reconocérseles la justificación. Dicho de otra forma, en los casos en que las reacciones neurobiológicas del organismo dificulten notoriamente o impidan optar por el medio menos lesivo, no rige la regla de opción del medio menos lesivo, pudiendo igualmente reconocerse en estos casos la justificación por legítima defensa, considerándose que ha habido "necesidad racional del medio empleado". Lo contrario mostraría una cierta irracionalidad de la regla, generando un trato jurídico diverso sobre la base de consideraciones que no dependen ni de la voluntad ni del actuar de las personas.

\section{La elección del medio menos lesivo: Un criterio que vuelve derrotable el principio de la defensa necesaria}

Si asumimos que la "opción de un medio menos lesivo" es una propiedad atribuida por medio de una generalización del enunciado normativo "defensa necesaria", ello puede generar, además de lo ya mencionado, importantes

122 Wessels (1980), pp. 110 y 111. 
problemas de derrotabilidad de la regla de defensa necesaria que se intenta construir para ser aplicada.

En efecto, la teoría de la derrotabilidad de las normas plantea que es posible no aplicar una regla, debiendo ser aplicada prima facie a un caso, cuando exista otra regla, un principio o circunstancia que la haga devenir en inaplicable y que tenga supremacía sobre la aplicación de la primera. Ello permitiría, por ejemplo, que el juez, basado en la equidad u otra idea similar, creara o aceptara una excepción a la aplicación literal de una regla general para un caso particular ${ }^{123}$.

De forma más precisa -aunque no por ello menos controvertida-, la idea de una norma "derrotable" o "abierta" quiere significar que una norma presenta excepciones implícitas que no pueden ser enumeradas exhaustivamente de antemano, de manera que no sería posible precisar por anticipado las circunstancias que operarían como genuina condición suficiente para su aplicación ${ }^{124}$. Desde esta perspectiva, cualquier norma jurídica puede ser expresada como un enunciado condicional "si $X$, entonces $Y$ ", donde el antecedente denota una clase de supuesto de hecho y el consecuente una clase de consecuencia jurídica. Así, muchas de las formulaciones normativas son derrotables, pues poseen circunstancias que derrotan la norma aunque ellas no estén explícitamente enunciadas ${ }^{125}$. Es decir, con derrotabilidad se quiere significar, en sentido amplio, una decisión "no final" -siempre revisable o rebatible, porque el conocimiento es falible- sobre la aplicación de una regla y, en un sentido estricto, la relación entre la presencia o ausencia de circunstancias derrotables y la corrección de una determinada decisión ${ }^{126}$.

Sin entrar en el espinudo tema de la derrotabilidad de las normas, uno de los criterios que se suele emplear es que la norma se vuelve derrotable o inaplicable cuando no se cumplen una serie de presupuestos aceptados en el contexto de su emisión, los cuales son unidos a su antecedente para formar una condición suficiente del consecuente. En el lenguaje corriente, las construcciones condicionales de forma "si A, entonces B" son frecuentemente usadas no solo con la finalidad de señalar que el antecedente $A$ es una condición suficiente del consecuente B, sino también para indicar que solo el antecedente, sumado al conjunto de presupuestos aceptados en el contexto de emisión del condicional, es condición suficiente del consecuente $\mathrm{B}^{127}$. Así, cuando estos presupuestos

123 BRIX (2012), pp. 200 y ss.

124 BAYÓn (2000), pp. 91 y ss.; En el mismo sentido, Guastinı (2008), pp. 145 y ss.

125 Guastini (2008), p. 145.

126 Duarte (2015), p. 23.

127 Alchourrón (2010), pp. 166 y ss. 
implícitos no se cumplen o no concurren, la construcción condicional es "derrotada"128. Por ejemplo, la regla de que el agua hierve a los $100^{\circ}$ Celsius es derrotada cuando se alteran las condiciones de presión atmosférica, porque dicha regla presupone que el agua se haga hervir "a nivel del mar". Desde esta perspectiva, la noción de derrotabilidad se encuentra asociada a la idea de normalidad, de forma que un condicional derrotable puede ser definido como un condicional sujeto a excepciones implícitas ${ }^{129}$.

Ello, llevado al plano de la defensa necesaria, implica que el criterio de la opción del medio menos lesivo presupone que el sujeto se encuentre en condiciones de normalidad -y no de peligro-, donde pueda realizar una operación racional y lógica como la exigida por la regla. Pareciere ser que dichas condiciones de normalidad permitirían una opción racional por el medio menos lesivo, más allá de un contexto de peligro. Si no existe dicho presupuesto, la regla del medio menos lesivo se vuelve derrotable. Precisamente, los estudios de la neurobiología citados muestran que una persona sometida a un peligro como el que genera una agresión ilegítima (sobre todo en los casos de amenaza vital) no presenta, en un alto porcentaje de probabilidad, los presupuestos de "normalidad" en que se basa la regla de opción del medio menos lesivo, por lo que dicho criterio es derrotable, pero no así la presencia general de una defensa necesaria.

Lo peligroso de lo anterior es que el criterio de la opción del medio menos lesivo se transforme en un requisito supralegal que restrinja indebidamente la aplicación de la legítima defensa. En efecto, el contexto normativo de la legítima defensa al interior del derecho penal no es para nada pacífico, pues no se tiene claridad acerca de si se trata de una permisión excepcional a la prohibición general (a partir de la cual podría sostenerse la especialidad de la norma de defensa legítima) o si, por el contrario, más bien norma prohibitiva y norma permisiva, desde el punto de vista de la teoría de los conjuntos, estarían en una relación de "interferencia", y no en una relación de "subordinación" o "inclusión", como lo exigiría la estimación de la norma permisiva como norma especial ${ }^{130}$. En efecto, no es para nada desacertado afirmar que la aplicación o no del criterio de la opción del medio menos lesivo esté condicionada, además, por los efectos penales del reconocimiento de la causal de justificación, entendida como excepción al régimen general de la prohibición. Ello, además de presu-

\footnotetext{
128 AgüERo (2015), pp. 154 y ss.

129 Alchourrón (2010), pp. 166 y 167. Para este mismo autor, la noción de normalidad es relativa al conjunto de creencias del hablante y al contexto de emisión: "Lo que resulta normal para una persona en cierto contexto puede ser anormal para otra persona o para la misma persona en un contexto diferente".

130 Mañalich (2013), p. 211.
} 
poner una posición sobre lo anterior, torna aún más complejo la problemática del sentido y alcance del criterio en análisis.

A mi modo de ver, el criterio de la opción del medio menos lesivo es derrotable, de acuerdo a las circunstancias del caso, cuya ausencia no debiera restringir la consideración de "defensa necesaria" de la respuesta de la víctima cuyo sistema neurobiológico no se encuentre en condiciones de "normalidad". Es decir, la regla "si se opta por el medio menos lesivo, entonces hay defensa necesaria" fracasa y, por tanto, no puede tenerse como una razón protegida ${ }^{131}$, alterando la posible estructura de la legítima defensa como una permisión basada en razones excluyentes ${ }^{132}$.

Ahora, con todo lo expuesto no quiero sugerir que el criterio de opción del medio menos lesivo sea completamente inconsistente. Puede servir como baremo de defensa necesaria en ciertos casos excepcionales ${ }^{133}$. Lo que afirmo es que no es un buen criterio que dé cuenta de la generalidad de los casos de defensas necesarias (es una generalización débil y derrotable), por un lado, ni menos puede ser tenido como requisito sine qua non para estimar necesaria la defensa que permita excluir la legítima defensa frente a su ausencia, por otro. Es decir, a mi modo de ver, la regla de opción del medio menos lesivo, aunque pudiera a llegar a tener valor en ciertos casos excepcionales (como cuando se recupera la "normalidad" no peligrosa o se neutralizan los efectos de la misma a través de la habituación del riesgo, por ejemplo ${ }^{134}$ ), no puede ser tenida como un criterio de procedencia general para valorar la "necesidad racional del medio empleado".

Frente a todo lo anterior, la situación no es otra que seguir trabajando para dotar de un contenido correcto al enunciado normativo "defensa necesaria", sobre la base de la valoración de las circunstancias específicas del caso, por un lado, y de las condiciones generales y contextuales de la víctima, por otro. Alguna finalidad tendrá que el legislador, precisamente en la materia, no haya expresado criterios de valoración.

\footnotetext{
131 Sobre derrotabilidad en relación con las prescripciones contenidas en la formulación normativa de las reglas y la justificación subyacente de las mismas, véase RódenAs (2001), p. 25.

132 Sobre las permisiones y razones excluyentes para acción, véase RAZ (1991), pp. 97 y ss.

133 Puede llegar a ser un criterio de apreciación de la defensa necesaria respecto de ciertos sujetos cuyas actividades, por ejemplo, generen una situación de habituación al peligro o al estrés, como podría ser el caso de la defensa necesaria de los policías.

${ }^{134}$ Este podría ser el caso de los policías, quienes poseen formación y entrenamiento para hacer mejor frente a las situaciones de peligro que genera su trabajo. Es decir, desde el punto de vista de la psicología, poseen elementos para construir conductualmente una habituación al riesgo.
} 


\section{Conclusiones}

El criterio de la elección del medio menos lesivo presenta variadas inconsistencias para que sea considerado como un requisito general que permita inferir que la acción defensiva fue racional y necesaria. En efecto, los estudios que se han realizado sobre las reacciones neurobiológicas del organismo frente a situaciones de peligro, como el que genera una agresión ilegítima, y los trabajos referidos a la toma de decisiones en contexto de peligro, indican que el criterio de opción por el medio menos lesivo para la defensa es una generalización débil, desde su arista descriptiva, para dar cuenta del fenómeno de la defensa necesaria. De otro lado, presenta inconsistencias desde el punto de vista de la operatividad de la regla.

En otro sentido, estas mismas consideraciones muestran que la construcción de la regla de concurrencia de la defensa necesaria tomando como antecedente la elección del medio menos lesivo es completamente derrotable, pues en las situaciones defensivas no se dan los presupuestos de contexto que se asumen como concurrentes por el mismo criterio. De la misma forma, los déficits operativos de la regla pueden considerarse un indicador de que la misma no cumpliría con la máxima "debe implica puede", generando un problema importante si lo que se busca con ella es determinar la conducta defensiva de los ciudadanos.

Con todo, la regla de opción del medio menos lesivo es inconsistente para ser aplicada con carácter general como criterio de apreciación de la "racionalidad del medio empleado", pues ello además generaría situaciones de infra- o subinclusividad en relación con la norma permisiva que autoriza la defensa legítima. Lo anterior, sin embargo, no excluye su consistencia para ser aplicada en casos excepcionales.

Todo lo anterior muestra que es al menos jurídicamente inconsistente aceptar la regla de opción del medio menos lesivo como de aplicación general y como un requisito de la necesariedad de la defensa para dar curso a la justificación por legítima defensa.

\section{BibLIOGRAFíA CITADA}

Agüero SAn Juan, Sebastián (2015): La derogación. Tesis doctoral (Barcelona, Universidad Pompeu Fabra).

Alchourrón, Carlos (2010): "Sobre derecho y lógica", en: Alchourrón, Carlos, Fundamentos para una teoría general de los deberes (Madrid/Barcelona/Bs. Aires, Marcial Pons), pp. 155-176.

Avishal, S.; Brunson, K.; Sandman, C.; Baram, T. (2002): "Stressed-out or in (utero)?", en: Trends Neurosci (Vol. 25, No 10), pp. 518- 524. 
Bayón Mohíno, Juan Carlos (2000): "Derrotabilidad, indeterminación del derecho y positivismo jurídico", en: Isonomía: Revista de Teoría y Filosofía del Derecho (№13), pp. 87-117.

Baldó Lavilla, Francisco (1994): Estado de necesidad y legítima defensa (Barcelona, Bosch).

BAldó LAVILla, Francesc (2016): Estado de necesidad y legítima defensa, $2^{\text {a }}$ edición (Montevideo/Buenos Aires, B de F).

BAKER, D. (1995): "Intrauterine programming of adult disease", en: Molecular Medicine Today ( $\left.N^{\circ} 1\right)$, pp. 418-423.

BeluINI, Federico (2006): La difesa legittima (Torino, Giappicheli Editore).

Bolea Bardon, Carolina (1998): "El exceso intensivo en la legítima defensa putativa", en: Anuario de Derecho Penal y Ciencias Penales (Vol. LI), pp. 614-641.

BuCKIGHAM, J. (2006): "Glucocorticoids: exemplars of multitasking", en: British Journal of Pharmacology (№ 147), pp. 258-268.

Bullemore, Vivian, y MaCkinnon, John (2005): Curso de Derecho Penal (Santiago, LexisNexis), Tomo II.

BRIX, Brian (2012): “Defeasibility and open texture", en: Ferrer Beltrán, Jordi, y Battista Ratti, Giovanni (Editores), The Logic of Legal Requirements: Essays on Defeasibility (Oxford, Oxford University Press), pp. 193-201.

Cobo del Rosal, Manuel (2011): Sinopsis de derecho penal. Parte general (Madrid, Dykinson).

Corcor Bidasolo, Mirentxu (1989): El delito imprudente (Barcelona, PPU).

Cousiño MAC IVER, Luis (1979): Derecho penal chileno (Santiago, Editorial jurídica de Chile), Tomo II.

Cuello Contreras, Joaquín, y Mapelli Caffarena, Borja (2011): Curso de derecho penal. Parte general (Madrid, Tecnos).

Curr UrZúA, Enrique (2005): Derecho penal. Parte general, 7ª edición (Santiago, Ediciones Universidad Católica de Chile).

Chrousos, G.; Gold, P. (1992): "The concepts of stress and stress system disorders. Overview of physical and behavioral homeostasis", en: Jama ( $\left.N^{\circ} 267\right)$, pp. 1244-1252.

De Kloet, E.; Joëls, M., y Holsboer, F. (2005): "Stress and the brain: from adaptation to disease", en: Nature Reviews Neuroscience ( $\mathrm{N}^{\circ}$ 6), pp. 463-475.

Diez Ripollés, José Luis (2011): Derecho penal español. Parte general. En esquemas, $3^{\text {a }}$ edición (Valencia, Tirant lo Blanch). 
DWORKIN, Ronald (1989): Los derechos en serio (Traducc. Marta Guastavino, Barcelona, Ariel).

DuARTE D'ÁLMEIDA, Luis (2015): Allowing for exceptions: a theory of defences and defeasibility in Law (Oxford, Oxford University Press).

EnDicotT, Timothy (2006): La vaguedad en el derecho (Traducc. J. Alberto del Real Alcalá, Juan Vega Gómez, Madrid, Dykinson).

Elliott, Catherine, y Quinn, Frances (2016): Criminal Law. $11^{\text {th }}$ edition (Edimburgh, Pearson).

Etcheberry Orthusteguy, Alfredo (1997): Derecho penal. Parte general, $3^{\text {a }}$ edición (Santiago, Editorial Jurídica de Chile), Tomo II.

Feuerbach, Paul Johann Anselm Ritter von (1989): Tratado de derecho penal (Traducc. Eugenio Zaffaroni e Irma Hagemeler, Buenos Aires, Hammurabi).

GaRDNeR, John (2012): "Justificaciones y razones", en: Garder, John, Ofensas y defensas (Traducc. de María Laura Manríquez y José Milton Peralta, Barcelona/ Madrid/ Buenos Aires/Sao Paulo, Marcial Pons), pp. 113-142.

Garnham, Alan, y OAKHILL, Jane (1996): Manual de psicología del pensamiento (Traducc. Eva Juarrós Daussá, Barcelona/Bs. Aires/México, Paidós).

Garrido Montt, Mario (2003): Derecho penal. Parte general, $3^{\text {a }}$ edición (Santiago, Editorial Jurídica de Chile), Tomo II.

GUASTINI, Riccardo (2014): Interpretar y argumentar (Traducc. Silvina Álvarez, Madrid, Centro de Estudios Políticos y Constitucionales).

GuastinI, Riccardo (2008): "Variaciones sobre temas de Carlos Alchourrón y Eugenio Bulygin. Derrotabilidad, lagunas axiológicas e interpretación", en: Doxa (No 31), pp. 143-156.

Hart, H. L. A. (1998): El concepto de derecho (Traducc. Genaro Carrió, Bs. Aires, Abeledo Perrot).

JakoBs, Günther (1997): Derecho penal. Parte general, $2^{a}$ edición (Traducc. Joaquín Cuello Contreras y José Luis Serrano González de Murillo, Madrid, Marcial Pons).

JeSCHECK, Hans-Heinrich, y WeIGend, Thomas (2002): Tratado de derecho penal. Parte general, $5^{\text {a }}$ edición (Traducc. Miguel Olmedo Cardenete, Granada, Comares).

Jiménez De Asúa, Luis (2005): La teoría jurídica del delito (Madrid, Dykinson).

JoËıs, M. et al. (2006): "Learning under stress: how does it work?", en: Trends Cognitive Sciences ( $\left.\mathrm{N}^{\circ} 10\right)$, pp. 152-158.

Kaufmann, Armin (1997): Teoría de las normas (Traducc. de Enrique Bacigalupo y Ernesto Garzón Valdés, Bs. Aires, Depalma). 
(2006): Dogmática de los delitos de omisión (Traducc. de Joaquín Cuello y José Luis Serrano, Madrid/Barcelona, Marcial Pons).

KINDHÄUSER, Urs (2008): "El tipo subjetivo en la construcción del delito", en: InDret ( $\left.N^{\circ} 4\right)$, pp. 5-39.

(2013): "Acerca de la génesis de la fórmula 'el derecho no necesita ceder ante el injusto'", en: AA. VV., La antijuridicidad en el derecho penal (Buenos Aires/Montevideo, B de F), pp. 65-98.

Kudielka, Brigitte, y Kirschbaum, Clemens (2007): "Biological basis of the stress response", en: Al'absi, Mustafa (editor), Stress and addiction (Boston, Academic Press), pp. 3-19.

KLEIN, Gary (1998): Source of Power: How people make decisions (Cambridge/ London, The MIT Press).

(2008): "Naturalistic decision making", en: Human Factor (Vol. 50, $\left.\mathrm{N}^{\circ} 3\right)$, pp. 456-460.

(1989): "Strategies of decisions making", en: Military Review U.S. Navy (May), pp. 56-64.

López Barja De Quiroga, Jacobo (2010): Tratado de derecho penal. Parte general (Navarra, Civitas).

Luzón Cuesta, José María (2009): Compendio de derecho penal. Parte general, $19^{a}$ edición (Madrid, Dykinson).

Luzón Cuesta, Diego (2002): "Legítima defensa", en: Luzón, Diego (director), Enciclopedia penal básica (Granada, Comares), pp. 879 y ss. (2004): Curso de derecho penal. Parte general (Madrid, Ed. Universitas). (1978): Aspectos esenciales de la legítima defensa (Barcelona, Bosch).

MAURACH, Reinhart, y ZIPF, Heinz (1994): Derecho penal. Parte general (Traducc. de Jorge Bofill Genzsch y Enrique Aimone Gibson, Buenos Aires, Astrea).

MAGARIÑOS, A. et al. (1997): "Chronic stress alters synaptic terminal structure in hippocampus", en: Proceedings of the National Academy of Science of the United States of America ( No 94), pp. 14002-14008.

Mañalich RAFFo, Juan (2013): "Normas permisivas y deberes de tolerancia", en: AA. VV., La antijuridicidad en el derecho penal (Buenos Aires/Montevideo, B de F), pp. 177-283.

Matellanes Rodríguez, Nuria (2010): "Las causas de justificación: teoría general", en: Berdug, Ignacio (coordinador), Lecciones y materiales para el estudio del derecho penal (Madrid, lustel), Tomo II, pp. 239-262.

MARANHAO, Juliano (2016): "La lógica de la implicación normativa de Von Wright y la paradoja de Chisholm", en: Doxa (№ 36), pp. 65-84. 
MCewen, Bruce (2008): "Central effects of stress hormones in health and disease: Understanding the protective and damaging effects of stress and stress mediators", en: European Journal of Pharmacology ( $N^{\circ}$ 583), pp. 174-185.

MIR PUIG, Santiago (2015): Derecho penal. Parte general, $10^{a}$ edición (Barcelona, Reppertor).

Morillas Cueva, Lorenzo (2004): Derecho penal. Parte general (Madrid, Dykinson). Muñoz Conde, Francisco, y García Arán, Mercedes (2010): Derecho penal. Parte general, $8^{a}$ edición (Valencia, Tirant lo Blanch).

Nieva Fenoll, Jordi (2010): La valoración de la prueba (Barcelona, Marcial Pons).

Olivares Rodríguez, Ernesto (2013): "El estado de necesidad racional de la legítima defensa. Análisis jurisprudencial sobre la forma de apreciar la necesidad racional del medio empleado frente a la agresión ilegítima", en: Política Criminal (Vol. 8, № 15), pp. 1-22.

Orts Berenguer, Enrique, y González Cussac, José (2008): Compendio de derecho penal. Parte general (Tirant lo Blanch, Valencia).

PACHECO, Joaquín Francisco (1848): El Código Penal concordado y comentado (Madrid, Imprenta de Santiago Saunaque), Tomo I.

Politoff Lifschitz, Sergio, y Matus Acuña, Jean Pierre (2002): "Comentario al art. 10 № 4 del Código Penal", en: Politoff, Sergio, y Quiroga, Luis (directores), Texto y comentario del Código Penal chileno (Santiago, Editorial Jurídica de Chile), Tomo I, pp. 127-144.

Politoff Lifschitz, Sergio; Matus Acuña, Jean Pierre, y Ramírez Guzmán, María (2003): Lecciones de derecho penal. Parte general, $2^{\text {a }}$ edición (Santiago, Editorial Jurídica de Chile).

Quintero Olivares, Gonzalo, y Morales Prats, Fermín (2010): Parte general del derecho penal, $4^{a}$ edición (Navarra, Aranzadi).

RAz, Joseph (1991): Razón práctica y normas (Traducc. Juan Ruiz Manero, Madrid, Centro de Estudios Constitucionales).

RódenAs Calatayud, Ángeles (2001): "En la penumbra: indeterminación, derrotabilidad y aplicación judicial de las normas", en: Doxa (No 24), pp. 63-83.

Rodríguez Ramos, Luis (2010): Compendio de derecho penal. Parte general, $2^{\text {a }}$ edición (Madrid, Dykinson).

Roxin, Claus (1997): Derecho penal. Parte general. (Traducc. Diego Luzón Peña, Miguel Díaz y Javier de Vicente Remesal, Madrid, Civitas), Tomo I.

(1982): "Las restricciones ético-sociales al derecho de legítima defensa", en: Cuadernos de Política Criminal (No 17), pp. 297-324. 
Sangero, Boaz (2006): Self-defence in Criminal Law (Oxford and Portland, Oregon, Hart Publishing).

SARNO, Franz, y SARnO, Manuel (2008): L'eoluzione della legittima difesa (Milano, Giuffrè Editore).

Schauer, Frederick (2004): Las reglas en juego (Traducc. Claudina Orunesu y Jorge L. Rodríguez, Madrid/Barcelona, Marcial Pons).

Stratenwerth, Günter (2005): Derecho penal. Parte general (Traducc. Manuel Cancio Meliá y Marcelo Sancinetti, Navarra, Cizur Menor/Thomson/Civitas). Selye, Hans (1937): "Studies on adaptation", en: Endocrinology (Vol. 21, № 2), pp. 169-189.

(1936): "A syndrome produced by diverse Nocuous Agents", en: British Journal Nature ( $\left.\mathrm{N}^{\circ} 138\right)$, p. 32.

SuÁrez-Mira, Carlos et al. (2011): Manual de derecho penal. Parte general, $6^{a}$ edición (Navarra, Civitas).

Silva SÁnchez, Jesús (1991): "Sobre los movimientos impulsivos y el concepto jurídico-penal de acción", en: ADPCP (Vol. XLIV), pp. 1-23.

TARUFFO, Michele (2009): "Consideraciones sobre las máximas de experiencia", en:TARuffo, Michele, Páginas sobre justicia civil (Madrid/Barcelona/Bs. Aires, Marcial Pons), pp. 439-454.

Vera SÁnChez, Juan (2015): "Algunas variables político-criminales del proceso penal", en: Estudios Penales y Criminológicos (Vol. 35), pp. 1-57.

Villegas Díaz, Myrna (2010): "Homicidio de la pareja en violencia intrafamiliar. Mujeres homicidas y exención de responsabilidad penal", en: Revista de Derecho. Valdivia (Vol. XXIII, No 2), pp. 149-174.

VON Wright, Georg (1979): Norma y acción (Traducc. Pedro García Ferrero, Madrid, Editorial Tecnos).

VON WRIGHT, Georg (1997): "Ser y deber ser", en: AA. VV., La normatividad del derecho (Barcelona, Gedisa), pp. 87-109.

Waismann, F. (1945): "Verifiability. Proceedings of the Aristotelian Society, Supplementary volume XIX", en: Analysis and Metaphysics (Vol. 12, № 3), pp. 119-150.

Welzel, Hans (1976): Derecho penal alemán. Parte general, $2^{a}$ edición (Traducc. Juan Bustos Ramírez y Sergio Yánez Pérez, Santiago, Editorial Jurídica de Chile). (1987): Derecho penal alemán. Parte general, $3^{\text {a }}$ edición (Traducc. Juan Bustos Ramírez y Sergio Yánez Pérez, Santiago, Editorial Jurídica de Chile). 
WeSSELS, Johannes (1980): Derecho penal. Parte general (Traducc. Conrado Finzi, Buenos Aires, Ediciones Depalma).

Wessels, Johannes, y Beulke, Werner (2006): Strafrecht Allgemeiner Teil. 36 Auflage (Heildelberg, C.F. Müller Verlag).

Wilenmann Von Bernath, Javier (2015): "Injusto y agresión en la legítima defensa. Una teoría jurídica de la legítima defensa", en: Política Criminal (Vol. 10, No 20), pp. 622-677.

Zııı, Jacson (2012): Legítima defensa (Buenos Aires, Didot).

Zugaldía Espinar, José Miguel (2010): Fundamentos de derecho penal. Parte general, $4^{\text {a }}$ edición. (Valencia, Tirant lo Blanch).

\section{JURISPRUDENCIA CITADA}

Ministerio Público con Enrique Araya Urzúa (2016): Sentencia de Corte de Apelaciones de San Miguel, 14 de julio de 2016 (recurso de nulidad), en: Westlaw Chile CL/Jur/4986/2016.

Ministerio Público con Alex Guzmán Gonzales (2014): Sentencia de Corte de Apelaciones de Antofagasta, 8 de mayo de 2014 (recurso de nulidad), en: Westlaw CL/JUR/2283/2014.

Segundo Juzgado del Crimen de Puerto Montt con José Simón Villarroel Torres (2005): Sentencia Corte Suprema, 3 de mayo de 2007 (recurso de casación en la forma), en: Westlaw CL/JUR/5858/2007.

Lagos Muñoz, Marisa Andrea contra Tribunal de Juicio Oral en lo Penal de Valdivia (2004): Sentencia de la Corte de Apelaciones de Valdivia, 23 de diciembre de 2004 (recurso de nulidad), en: Westlaw Chile CL/JUR/132/2004.

Héctor Arnoldo Rubio contra Décimo Noveno Juzgado del Crimen de Santiago (2005): Sentencia de Corte Suprema, 17 de octubre de 2005 (recurso de casación en el fondo), en: Westlaw CL/JUR/1669/2005.

Ministerio Público contra Pedro Alejandro Henríquez Gutiérrez (2005): Sentencia de Corte de Apelaciones de la Serena, 6 de mayo de 2005 (recurso de nulidad), en: Westlaw CL/JUR/693/2005.

España:

Sentencia Tribunal Supremo, № 962/2005, Sala 2a , de lo Penal, de 22 de julio, FJ 3, ponente Julián Artemio Sánchez Melgar. 
